\title{
Estimation of body weight and body condition score in dairy cows by digital image analysis method
}

\author{
Mehmet Kaya ${ }^{1}$, Hüsnü Erbay Bardakçığlu ${ }^{1}$ \\ ${ }^{1}$ Department of Animal Science, Faculty of Veterinary Medicine, Aydın Adnan Menderes University, Aydın/TURKEY
}

\section{Key Words: \\ body condition score body weight conventional method digital image analysis method holstein}

$\begin{array}{ll}\text { Received } & : 06.07 .2021 \\ \text { Accepted } & : 07.10 .2021 \\ \text { Published Online }: 31.12 .2021 \\ \text { Article Code } & : 963188\end{array}$

Correspondence:

M. KAYA

(mehmet.kaya@adu.edu.tr)

\begin{abstract}
In this study the body weight (BW) and body condition score (BCS) of lactating cows was estimated by using the digital image analysis methods (DIAM). BCS is an important factor to facilitate different practices of management in dairy cattle. A total of 204 Holstein cows live images were taken by remote shutter camera. Six body measurements such as heart girth (HG), wither height $(\mathrm{WH})$, hip height $(\mathrm{HH})$, body length (BL), front hip-width (FHW), and back hip-width (BHW) were used for the assessment of BW and BCS by conventional (CM) and DIAM. The estimation of CBW using HG, FHW, and BL variables was effective $\left(\mathrm{R}^{2}=0.75\right)$. However, all the body measurements were ineffective for body condition score by measurements (MBCS), $\left(\mathrm{R}^{2}=0.06\right.$, conventional) and DBCS $\left(\mathrm{R}^{2}=0.05\right.$, digital) estimation. The measurements of $\mathrm{WH}, \mathrm{HG}, \mathrm{FHW}$, $B H W$, and BL were precise in DBW estimation $\left(\mathrm{R}^{2}=0.77\right)$. No significant differences were found across the assessment methods (CM, DIAM) for body measurements. The intra-class reliability coefficient (ICC) of conventional and digital (MBW, DBW) measurements was "good" and "excellent" between conventional and digital estimations. This study indicates that DIAM is a reliable method for determining DBW and MBW, and can be interchanged effectively with CM.
\end{abstract}

ORCID

M. KAYA :0000-0003-2377-4474

HE. BARDAKÇIOĞLU: 0000-0001-7634-1563

\section{INTRODUCTION}

The regulation of animal health and profitability of the commercial dairy farms is influenced by various management factors like feed intake, animal productivity, maintenance of body weight (BW), body condition score (BCS), and feeding program (1). The concept of automation has changed the face of dairy farming with innovative equipment's of feeding, milking, and heat detection. To maximize the profitability of dairy farms, BW and BCS is regularly monitored with conventional or automated techniques (2). Innovative technology for automatic detection of animals with poor body health can help to maximize milk yield, minimize veterinary costs, and improve herd management. The conventional methods (CM) of CBW and $\mathrm{CBCS}$ are prone to subjective variation and labor intensive for large dairy farms, moreover the observed data might be inconsistent during frequent measurements. Early detection of BCS can significantly reduce risks of developing lameness and various health problems (3). Therefore, monitoring the performance of the dairy animals i.e., body/health condition at key stages of parturition, mating and lactation is important to increase the productivity and profitability according to animal welfare criteria (4). Manual estimation of animal weight is performed by using specific anatomic points using livestock scale and weighing balance is used or BW measurement. The weighing devices are fixed in special area, this not only induces stress to animals but also interferes with normal dairy activities. Automated weighing devices are becoming more practi- cal, but this technology remains extremely costly (5). Recent studies reported that BW and BCS (digital BW and BCS, DBW and DBCS) can be estimated by using digital image analysis method (DIAM), (6,7). Furthermore, DIAM is not prone to subjective error by individual experts and can be conducted with low cost. Various benefits of this technology include continuous (24/7) monitoring of animals, based on quantitative data, rather than qualitative information, and digital imaging is more reliable than CM (8). Low-cost automatic collection and data analysis of DBW and DBCS for large herds is practically unavailable. Therefore, the aim of this study was to estimate BW and BCS of dairy animals by digital method and predict its reliability by regression model.

\section{MATERIAL and METHODS}

The study was conducted at a private intensive dairy farm in Aydin. In this study 204 Holstein cows were used. Animals with excessive weakness, posture disorder, and lameness, $6>$ months pregnant, under treatment or in dry period were excluded from the study in order to avoid the measurement errors. Similarly, cow age/parity, lactation stage or any other parameters were also excluded from the statistical method.

\section{Methods of body measurements}

Body measurements of dairy cattle were performed once with two methods, in first step with conventional method (CBW, CBCS) and in the second step digital image analysis method (DBW, DBCS). 


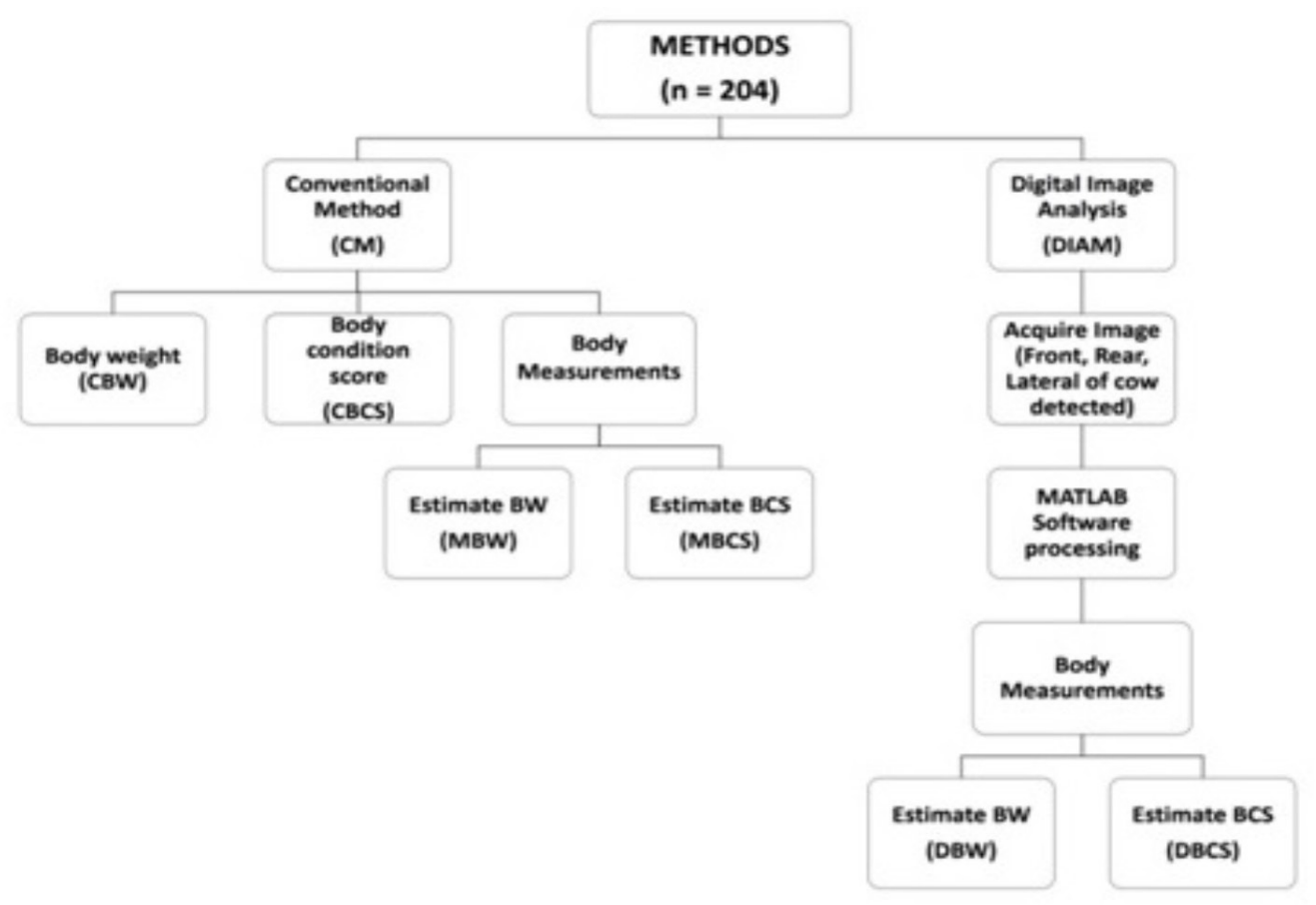

Figure 1. Represents the stepwise sequence of both procedures (conventional and digital) and the measurements with scale.

The stepwise sequence of both procedures (conventional and digital) and the measurements with scale was shown in Figure 1. Body weight (BW) and body condition score (BCS) were measured at each step. The body parts of the cows were examined by veterinarian according to the prominence of bone protrusion, muscle, and subcutaneous fat accumulation in a studio environment created for the animals in a separate area. The examination was controlled by palpation and inspection for BCS. The cows were kept stablewhile conducting the imaging procedure and measurements.

Measuring cane and tape were used to take body measurements and body weight (MBW) and body condition score (MBCS) evaluation was performed using California Technique (9).

\section{Image Collection and processing}

$\mathrm{BW}$ and BCS were estimated by using body measurements such as heart girth (HG), wither height $(\mathrm{WH})$, hip height $(\mathrm{HH})$, body length (BL), front hip-width (FHW), back hipwidth (BHW), and data was recorded to perform the imaging processing.

Images were taken with digital camera (Nikon D3200) and the remote shutter release system synchronized cameras were utilized in a studio environment created for animals. Digital scales were determined to process the images by software with reference to the $\mathrm{BW}$ of animals. The evaluation of BCS and $\mathrm{BW}$ by digital imaging method was performed on images of the animals from four different directions (front, back, top, and side). The images were then processed and analyzed in the Digital Image Analysis Program (MATLAB-Image Processing Toolbox).

\section{Statistical Analysis}

All the data were analyzed by using SPSS ${ }^{\odot} 22.0$ (Statistical Package for the Social Sciences 22). In terms of body measurements, groups were determined as conventional and digital image analysis methods and compared by paired-samples t-test. The reliability analysis was performed by finding high correlations between the given measurements and BW and BCS values to evaluate the reliability of the data. The results were interpreted by test-retest reliability analysis and the absolute agreement between conventional and digital image analysis methods was determined separately. The variables (BW, BCS) with high association were considered reliable. Similarly, the level of absolute agreement between the methods, and intraclass correlation coefficient (ICC) was estimated (10). Multiple linear regression analysis was also used to estimate $\mathrm{BW}$ and BCS in conventional and digital image analysis methods. The estimation of BW and BCS using regression model was defined as " $\hat{y}=a+\beta 1 \times x 1+\beta 2 \times x 2+\beta 3 \times x 3$ " where $\hat{y}$ is the depend variable $(B W, B C S)$ of cow, $a$ is the intercept; $\beta 1, \beta 2$, and $\beta 3$ are regression coefficients corresponding to the co-variables heart girth $(\mathrm{HG})$, wither height $(\mathrm{WH})$, hip height $(\mathrm{HH})$, body length (BL), front hip-width (FHW), and back hip-width (BHW) respectively. "Enter method" was applied to all variables to examine the correlation between independent variables in terms of model fit. Afterwards "Backward, Forward, and Stepwise" methods were applied for the important parameters. Data were presented as the mean \pm standard error and $\mathrm{P}<0.05$ was considered as statistically significant (11).

\section{RESULTS}

BW and BCS of cows were $629.10 \mathrm{~kg}$ and 3.05 for CM and for DIAM $628.62 \mathrm{~kg}$ and 2.96, respectively. Correlation of 
CBW and CBCS $(r=0.40)$ was found significant $(\mathrm{P}<0.001)$. In $\mathrm{CM}$ the body measurements were utilized effectively for estimation of body weight (MBW) and highest correlation ( $\mathrm{r}=$ 0.71 ) was found between $\mathrm{HH}$ and $\mathrm{WH}$; and lowest correlation $(\mathrm{r}=0.22)$ was found between BHW and HH. Similarly, for DIAM showed highest correlation $(r=0.86)$ between $\mathrm{HH}$ and $\mathrm{WH}$, and lowest correlation $(\mathrm{r}=0.31)$ between $\mathrm{BHW}$ and $\mathrm{HH}$ $(\mathrm{P}<0.001)$ was found. showed that HG, BL, FHW and BHW (independent variables) have significant effect $\left(\mathrm{R}^{2}=0.77\right)$. But for $\mathrm{BCS}$ the parameters like $\mathrm{HG}$ and $\mathrm{BHW}$ (independent variables) were found to be non-significant $\left(\mathrm{R}^{2}=0.05\right)$.

No significant differences were found for WH, HH, HG, FHW, BHW and BL values of the cows between both methods (Table 2).

Table 1. Shows estimation of BW and BCS of dairy cattle by using both methods (CM, DIAM) of body conformation using regression analysis.

\begin{tabular}{ccc}
\hline \multicolumn{1}{c}{ Method } & Regression equation & $\mathbf{R}^{2}$ \\
\hline Conventional & $\mathrm{BW}(\mathrm{MBW})=-1016.827+5.402 \times \mathrm{HG}+5.273 \times \mathrm{FHW}+1.864 \times \mathrm{BL}$ & 0.75 \\
Conventional & $\mathrm{BCS}(\mathrm{MBCS})=1.493+0.014 \times \mathrm{HG}-0.054 \times \mathrm{BHW}$ & 0.06 \\
Digital & $\mathrm{BW}(\mathrm{DBW})=-1060.360+5.100 \times \mathrm{HG}+2.564 \times \mathrm{BL}+3.099 \times \mathrm{FHW}+5.255 \times \mathrm{BHW}$ & 0.77 \\
Digital & $\mathrm{BCS}(\mathrm{DBCS})=1.222+0.017 \times \mathrm{HG}-0.027 \times \mathrm{FHW}$ & 0.05 \\
\hline
\end{tabular}

Table 2. Shows comparison of both methods (CM, DIAM) used to body measurements $\left(\mathrm{x} \mathrm{s}_{\mathrm{e}}\right),(\mathrm{n}=204)$

\begin{tabular}{cccc}
\hline Body measurements & \multicolumn{2}{c}{ Method } & P \\
& Conventional & Digital & \\
\hline WH & $148.04 \pm 0.27$ & $147.88 \pm 0.31$ & 0.443 \\
HH & $146.52 \pm 0.24$ & $146.83 \pm 0.30$ & 0.115 \\
FHW & $57.31 \pm 0.23$ & $57.12 \pm 0.22$ & 0.086 \\
BHW & $21.84 \pm 0.09$ & $21.84 \pm 0.08$ & 0.916 \\
BL & $160.34 \pm 0.45$ & $160.67 \pm 0.46$ & 0.236 \\
HG & $193.43 \pm 0.56$ & $193.26 \pm 0.57$ & 0.224 \\
\hline
\end{tabular}

$\overline{\mathrm{x}}$ : Mean, $\mathrm{s}_{\mathrm{e}}$ : Standard error

Regression coefficients of independent variables were found to have significance between the studied parameters and are given in Table 1. In CM, the parameters like HG, FHW and BL (independent variables) were significant $\left(\mathrm{R}^{2}=0.75\right)$ for the estimation of body weight; however, for the BCS (depen-dent) HG and BHW (independent variables) were found to be non-significant $\left(\mathrm{R}^{2}=0.06\right)$. In the DIAM, BW estimation
Table 3 shows the reliability analysis of both methods for BW andBCS; Cronbach's alpha coefficient $(\alpha)$ and intra-class correlation coefficient (ICC) were in an absolute agreement $(\mathrm{P}<0.001)$ for the WH, HH, HG, FHW, BHW, and BL for CM and DIAM. 
Table 3. Reliability analysis between methods (CM, DIAM) for body measurements $(\mathrm{n}=204)$

\begin{tabular}{cccccc}
\hline Body measurements & Reliance range* & $\alpha$ & ICC & F & P \\
\hline WH & $0.70-0.81$ & 0.86 & 0.76 & 7.54 & 0.000 \\
HH & $0.68-0.80$ & 0.85 & 0.75 & 7.04 & 0.000 \\
FHW & $0.85-0.91$ & 0.94 & 0.89 & 17.50 & 0.000 \\
BHW & $0.72-0.83$ & 0.87 & 0.78 & 8.24 & 0.000 \\
BL & $0.76-0.86$ & 0.90 & 0.82 & 10.11 & 0.000 \\
HG & $0.95-0.97$ & 0.98 & 0.96 & 61.09 & 0.000 \\
\hline
\end{tabular}

*: $95 \%$

Table 4. Some descriptive statistics of

$\mathrm{BW}$ and $\mathrm{BCS}\left(\overline{\mathrm{x}} \pm \mathrm{s}_{\mathrm{e}}\right),(\mathrm{n}=204)$

\begin{tabular}{ll}
\hline & $\overline{\mathbf{x}}_{\mathbf{1}} \mathbf{s}_{\mathrm{e}}$ \\
\hline $\mathrm{CBW}$ & $629.10 \pm 5.15$ \\
$\mathrm{MBW}$ & $629.21 \pm 4.47$ \\
$\mathrm{DBW}$ & $629.04 \pm 4.53$ \\
CBCS & $3.05 \pm 0.03$ \\
MBCS & $3.02 \pm 0.00$ \\
DBCS & $2.96 \pm 0.00$ \\
\hline
\end{tabular}

$\overline{\mathrm{x}}$ : Mean, $\mathrm{s}_{\mathrm{e}}$ : Standard error

Table 5. Reliability analysis for BW and BCS $(\mathrm{n}=204)$

\begin{tabular}{lccccc}
\hline & Reliance range $*$ & $\alpha$ & ICC & F & P \\
\hline CBW - MBW & $0.82-0.89$ & 0.92 & 0.86 & 13.28 & 0.000 \\
CBW - DBW & $0.83-0.90$ & 0.93 & 0.87 & 14.60 & 0.000 \\
MBW - DBW & $0.95-0.97$ & 0.98 & 0.96 & 54.86 & 0.000 \\
CBCS - MBCS & $-0.02-0.24$ & 0.20 & 0.11 & 1.25 & 0.054 \\
CBCS - DBCS & $-0.03-0.22$ & 0.18 & 0.09 & 1.22 & 0.079 \\
MBCS - DBCS & $0.27-0.71$ & 0.77 & 0.55 & 4.50 & 0.000 \\
\hline
\end{tabular}

*: $95 \%$

The mean values estimated by CM or DIAM i.e., MBW, MBCS, DBW, DBCS and the CBW and CBCS were measured by body measurements are shown in Table 4.

Reliability analysis was performed for the measurement compliance between CM and DIAM. The reliability analysis determined that body measurement parameters were significant $(\mathrm{P}<0.001)$ for CBW - MBW, CBW - DBW, and CBCS - DBCS (Table 5).

\section{DISCUSSION}

The benefits of regular monitoring of BW in intensive dairy farms are well known to most of the dairy producers. The profitability of dairy enterprise solely depends on health of animals, and various issues of nutrition especially in early lactation can be controlled easily with body condition scoring (12). In the past few years, producers' interest has therefore grown in various estimation procedures of body conformation. BCS is well known due to its low cost and easy incorporation in dairy management (13). Traditional methods (CBW and CBCS) are simple but demand long hours of commitment from skilled observers. There is likelihood of variation in body measurements also and lack of practicality at big dairy farms. Therefore, such concerns have paved the way for digital/automated system of BCS in dairy animals. Both methods (CM, DIAM) estimated CBW, DBW effectively and further processed for regression analysis to understand the relationship with body measurements. The reliability analysis for MBW showed 
that regression parameters HG, FHW and BL were 5.402, 5.273 and 1.864 respectively; and the coefficient of determination $\left(\mathrm{R}^{2}\right)$ was 0.75 . This clearly shows that the body measurements can be used for MBW estimation accurately. Using the DIAM, regression parameter HG, BL, FHW and BHW were found significant $\left(\mathrm{R}^{2}=0.77\right)$ for DBW. BHW added as an extra parameter of body measurement in the DIAM. In this study both methods of body conformation assessment showed non-significant results for MBCS, DBCS $\left(\mathrm{R}^{2}=0.06\right.$ for $\mathrm{CM}$ and $\mathrm{R}^{2}=0.05$ for DIAM). In the literature $\mathrm{BCS}$ using the body measurements are reported to be not feasible practically. Taşdemir (14) reported that MBW estimation with body measurements (WH, HH, BL, HW), is possible $\left(\mathrm{R}^{2}\right.$ was 0.64$)$ and Kuzuhara et al. (15) found coefficient of determination for MBW $\left(\mathrm{R}^{2}=0.80\right)$ and MBCS $\left(\mathrm{R}^{2}=0.74\right)$ values via obser-vation and estimations from thurls, hook and pin bones of da-iry cows. Researchers have identified 23 anatomical points for BCS estimation by regression model $(16,17)$. Heinrichs et al. (18) predicted that heart girth can estimate the MBW, similarly highest $\mathrm{R}^{2}$ value was determined for the heart girth by (19). However, in several studies, it is reported that the measure-ment of heart girth might vary according to the BW categories of the animals $(20,21,22,23)$. Therefore, the differences of selected animals in the studies and the measurement accuracy of variables can cause differences between the results.

Hansen et al. (5) acknowledged the accuracy of the results of the digital image analysis method and suggested that DIAM methods were better for estimation of DBW and DBCS than the conventional method in dairy cows. Various studies have reported accurate digital systems to determine composition of body in dairy buffalo (24) and Zebu cattle (25). Negretti et al. (24) reported BW and BCS estimations as $\mathrm{R}^{2}=0.94$ and 0.92 , by digital image analysis in dairy cows, which is hig-her to our study $\left(\mathrm{R}^{2}=0.77\right)$, this difference might be due to the image analysis by MATLAB software. Taşdemir (14) declared that the regression coefficient values for $\mathrm{BL}$ and $\mathrm{HW}$ were 2.05 and 7.86, in 220 Holstein dairy cows. The regression coefficient determined for $\mathrm{BL}$ was similar with the findings of our study. A study was conducted in 229 dairy cows for the estimation of DBW an error value of $11.7 \%$ was reported (26). The variation in the results is possible due to selection differences of point, posture and position of animals during imaging process and the lack of program sensitivity. In the current study, regression coefficients of HG and FHW were effective in DBCS estimation and determined to be 0.324 and -0.197 . In a study by Kuzuhara et al. (15), DBCS was determined using a three-dimensional camera system and mean value of 3.2 was reported, however in this study lower mean value of 2.96 was found.

The high correlation of digital and conventional body measurements is shows that DIAM can be easily incorporated in the form of digital or android application in mobiles or computers. But still the final output is an estimation of DBW. Unfortunately, the accurate estimation of DBW cannot give information of true energy reserves of cattle. This is the limitation of this study that the scale measurements can help in estimation of BW but much less useful for DBCS. In another study a three-dimensional imaging method was used to find the correlation coefficient of BCS value in 40 Holstein cows and it was determined to be 0.84 (27). The difference form other studies are possible due to lack of sensitivity of the program in our study and image processing in different digital image analysis methods. Furthermore, the diversity of body parts used for body measurements, age and sex differences of experimental animals have resulted in lower value in our study.

Özkaya et al. (28) found the correlation coefficients between the actual and predicted values of body measurements for $\mathrm{BL}, \mathrm{WH}, \mathrm{HH}$, and $\mathrm{HW}$ were $0.94 ; 0.95 ; 0.90$ and 0.78 . In the reliability analysis between both methods (CM, DIAM), intra-class correlation coefficient for HG was highest in our study. The reference points during heart girth estimation are easily accessible and this might be the reason of high accuracy for HG while measuring the body points. Stajnko et al. (29) reported that prediction of body weight with hip height was more accurate by using thermal image analysis. DIAM to estimate body conformation has advantage of better efficiency, being hygienic and risk free. However, CM instead requires skilled experts who travel between farms and increase the risks of disease transmission. DIAM method has another advantage of providing continuous dataflow for early warnings and management actions specially at bigger dairy farms $(4,30)$. The comparison between CBCS and DBCS useful in a sense to find out the practicality at farm level. Visual BCS assessment for CBCS assessment is easier but using the above mentioned six measurements is complex. Similarly, during the movement of cows from parlor to the barn digital images can be taken on routine basis to figure out DBCS. The procurement of body measurements for DBCS is however time consuming if it is performed manually. Therefore, a program or android application can be developed for estimation of DBCS digitally. However, in this case, Cronbach's alpha coefficient is quite small (0.18, Table 5). The low agreement in this study claims that DIAM cannot reliably replace visual appraisal of BCS. But the CBW can be reliably replaced.

\section{CONCLUSION}

In conclusion DIAM methods can easily replace $\mathrm{CM}$ for the calculations of CBW in dairy animals. Both CM and DIAM methods provide fair estimates of $\mathrm{CBW}$ or DBW and CBCS, MBCS and between these methods high intra-class correlation coefficients were found. The results of this study suggest that the objective determination of DBW and MBW by DIMA can be estimated adequately. Furthermore, explorative studies for DBCS using camera technology are suggested for future.

\section{DECLARATIONS}

\section{Ethics Approval}

The Animal Care and Practice, Committee of Aydin Adnan Menderes University approved all procedures involved in this experimental study (64583101/2014/115-08-2014).

\section{Conflict of Interest}

The authors declared that there are no conflicts of interest.

\section{Author Contribution}

Idea, concept and design: MK, HEB

Data collection and analysis: MK, HEB, MTM

Drafting of the manuscript: MK 
Critical review: MK, HEB

\section{Data Availability}

The data that support the findings of this study are available from the corresponding author upon reasonable request.

\section{Acknowledgements}

The research was summarized from a $\mathrm{PhD}$ thesis of the same name. The authors wish to gratefully acknowledge Aydin Adnan Menderes University (Aydin, Turkey) for financial supporting (Project No: VTF-15040) the present study. They are also grateful to Mustafa Tayfun MAVIOGLU, Department of Electronic Technology, Vocational School, Aydin Adnan Menderes University, Turkey for the coding/algorithm and Sanan RAZA, Department of Reproduction \& Artificial Insemination, Faculty of Veterinary Medicine, Aydin Adnan Menderes University, Turkey for revising the language of the manuscript.

\section{REFERENCES}

1. Sarı M, Çerçi İH, Deniz S, Şahin K, Seven PT, Şahin N, Çiftçi M, Bolat D, Önol AG, Azman MA, Güler T, Marslı MA, Nursoy H, Bingöl NT. Hayvan Besleme ve Beslenme Hastalıklar1. 1st ed., Malatya: 2008:178-207.

2. Frost AR, Schofield CP, Beaulah SA, Mottram TT, Lines JA, Wathes CM. A review of livestock monitoring and the need for integrated systems. Computers and electronics in agriculture. 1997 May 1;17(2):139-59.

3. Green LE, Huxley JN, Banks C, Green MJ. Temporal associations between low body condition, lameness and milk yield in a UK dairy herd. Preventive Vet Med. 2014 Jan 1;113(1):63-71.

4. Janssen SJ, Porter CH, Moore AD, Athanasiadis IN, Foster I, Jones JW, Antle JM. Towards a new generation of agricultural system data, models and knowledge products: Information and communication technology. Agricultural Syst.2017;155:200-212.

5. Hansen MF, Smith ML, Smith LN, Jabbar KA, Forbes D. Automated monitoring of dairy cow body condition, mobility and weight using a single $3 \mathrm{D}$ video capture device. Computers in industry. 2018 Jun 1;98:14-22.

6. Spoliansky R, Edan Y, Parmet Y, Halachmi I. Development of automatic body condition scoring using a lowcost 3-dimensional Kinect camera. J. Dairy Sci. 2016 Sep $1 ; 99(9): 7714-25$.

7. Bozkurt Y, Mikail N, Ulusar UD, Aktas H, Dogan C. Prediction Of Bodyweight Of Holstein And Brown-Swiss Male Cattle By Using Digital Images. Scientific Papers: Series D, Animal Science-The International Session of Scientific Communications of the Faculty of Animal Science. 2017 Jan 1;60.

8. Song X, Bokkers EA, van der Tol PP, Koerkamp PG, Van Mourik S. Automated body weight prediction of dairy cows using 3-dimensional vision. J. Dairy Sci. 2018 May $1 ; 101(5): 4448-59$.

9. Edmonson AJ, Lean IJ, Weaver LD, Farver T, Webster G. A body condition scoring chart for Holstein dairy cows. J. Dairy Sci. 1989;72(1):68-78.
10. Spor AR. Sağlık ve Eğitim Bilimlerinden Örneklerle Uygulamalı İstatistik ve Geçerlilik-Güvenirlilik.(4. Baskı). Ankara. Detay Yayınc1lik. 2016:513-557.

11. Özdamar L, Ertem MA. Models, solutions and enabling technologies in humanitarian logistics. European Journal of Operational Research. 2015 Jul 1;244(1):55-65.

12. Wangchuk K, Wangdi J, Mindu M. Comparison and reliability of techniques to estimate live cattle body weight. J. appl. ani. res. 2018 Jan 1;46(1):349-52.

13. Kristensen E, Dueholm L, Vink D, Andersen JE, Jakobsen EB, Illum-Nielsen S, Petersen FA, Enevoldsen C. Within-and across-person uniformity of body condition scoring in Danish Holstein cattle. J. Dairy Sci.2006 Sep 1;89(9):3721-8.

14. Taşdemir Ş. Dijital görüntü analiz yöntemi ile siyah alaca ineklerde vücut ölçülerinin belirlenmesi ve canlı ağırlı̆̆ının tahmin edilmesi (Doctoral dissertation, Selçuk Üniversitesi Fen Bilimleri Enstitüsü). 2010. Turkey.

15. Kuzuhara Y, Kawamura K, Yoshitoshi R, Tamaki T, Sugai S, Ikegami M, Kurokawa Y, Obitsu T, Okita M, Sugino T, Yasuda T. A preliminarily study for predicting body weight and milk properties in lactating Holstein cows using a three-dimensional camera system. Computers and Electronics in Agriculture. 2015 Feb 1;111:186-93.

16. Bewley JM, Peacock AM, Lewis O, Boyce RE, Roberts DJ, Coffey MP, Kenyon SJ, Schutz MM. Potential for estimation of body condition scores in dairy cattle from digital images. J. Dairy Sci. 2008 Sep 1;91(9):3439-53.

17. Azzaro G, Caccamo M, Ferguson JD, Battiato S, Farinella GM, Guarnera GC, Puglisi G, Petriglieri R, Licitra G. Objective estimation of body condition score by modeling cow body shape from digital images. J. Dairy Sci. 2011 Apr $1 ; 94(4): 2126-37$.

18. Heinrichs AJ, Rogers GW, Cooper JB. Predicting body weight and wither height in Holstein heifers using body measurements. J. Dairy Sci. 1992 Dec 1;75(12):3576-81.

19. Enevoldsen C, Kristensen T. Estimation of body weight from body size measurements and body condition scores in dairy cows. J. Dairy Sci. 1997 Sep 1;80(9):1988-95.

20. Gunawan A, Jakaria J. Application of linear body measurements for predicting weaning and yearling weight of bali cattle. Animal Prod. 2010;12(3).

21. Rashid MM, Hoque MA, Huque KS, Talukder MA, Bhuiyan AF. Morphometric characterization of Brahman crossbred cattle and prediction of live weight using linear body measurements. Asian J. Med. Biol. Res. 2015;1(3):569-77.

22. Heinrichs AJ, Heinrichs BS, Jones CM, Erickson PS, Kalscheur KF, Nennich TD, Heins BJ, Cardoso FC. Verifying Holstein heifer heart girth to body weight prediction equations. Journal of dairy science. 2017 Oct 1;100(10):8451-4.

23. Tebug SF, Missohou A, Sourokou Sabi S, Juga J, Poole EJ, Tapio M, Marshall K. Using body measurements to estima- 
te live weight of dairy cattle in low-input systems in Senegal. J. Appl. Ani. Res. 2018 Jan 1;46(1):87-93.

24. Negretti P, Bianconi G, Bartocci S, Terramoccia S, Verna M. Determination of live weight and body condition score in lactating Mediterranean buffalo by Visual Image Analysis. Livestock Science. 2008 Jan 1;113(1):1-7.

25. Arias, N.A., Molina, M.L. and Gualdron, O. Estimate of the weight in bovine livestock using digital image processing and neural network. In 5th Iberoamerican Meeting on Optics and 8th Latin American Meeting on Optics, Lasers, and Their Applications. International Society for Optics and Photonics. 2004 October;5622:224-228.

26. Seo KW, Kim HT, Lee DW, Yoon YC, Choi DY. Image processing algorithm for weight estimation of dairy cattle. Journal of Biosystems Engineering. 2011;36(1):48-57.

27. Anglart D. Automatic estimation of body weight and body condition score in dairy cows using 3D imaging technique. 2014.

28. Özkaya S. Besi sığırlarında sayısal görüntü analizi ile can1 ağırlık ve karkas performansının tahmin edilmesi ve tahmin modelleri ile karşılaştırılması (Master dissertation, Süleyman Demirel Üniversitesi). 2006. Turkey.

29. Stajnko D, Brus M, Hočevar M. Estimation of bull live weight through thermographically measured body dimensions. Computers and Electronics in Agriculture. 2008 May 1;61(2):233-40.

30. Kashiha MA, Bahr C, Ott S, Moons CP, Niewold TA, Tuyttens F, Berckmans D. Automatic monitoring of pig locomotion using image analysis. Livestock Science. 2014 Jan 1;159:141-8. 